\title{
Dynamics of Mycoplasmal Conjunctivitis in the Native and Introduced Range of the Host
}

\author{
André A. Dhondt, ${ }^{1}$ Alexander V. Badyaev, ${ }^{2}$ Andrew P. Dobson, ${ }^{3}$ Dana M. Hawley, ${ }^{1,4}$ \\ Melanie J.L. Driscoll, ${ }^{1}$ Wesley M. Hochachka, ${ }^{1}$ and David H. Ley ${ }^{5}$ \\ ${ }^{1}$ Laboratory of Ornithology, Cornell University, 159 Sapsucker Woods Road, Ithaca, NY 14850 \\ ${ }^{2}$ Ecology and Evolutionary Biology, University of Arizona, Tucson, AZ \\ ${ }^{3}$ Ecology and Evolutionary Biology, Princeton University, Princeton, NJ \\ ${ }^{4}$ Ecology and Evolutionary Biology, Cornell University, Ithaca, NY \\ ${ }^{5}$ College of Veterinary Medicine, North Carolina State University, Raleigh, NC
}

\begin{abstract}
In 1994, Mycoplasma gallisepticum, a common bacterial poultry pathogen, caused an epidemic in house finches in the eastern part of their North American range where the species had been introduced in the 1940s. Birds with mycoplasmal conjunctivitis were reported across the entire eastern United States within 3-4 years. Here we track the course of the Mycoplasma gallisepticum epidemic as it reached native, western North American populations of the house finch. In 2002, Mycoplasma gallisepticum was first observed in a native house finch population in Missoula, MT, where it gradually increased in prevalence during the next 2 years. Concurrently, house finches with conjunctivitis were reported with increasing number in the Pacific Northwest. In native populations of the host, the epidemic expanded more slowly, and reached lower levels of prevalence than in the eastern, introduced range of the species. Maximal prevalence was about half in the Missoula population than in local populations in the East. Although many factors can contribute to these differences, we argue that it is most likely the higher genetic heterogeneity in western than in eastern populations caused the lower impact of the pathogen.
\end{abstract}

Key words: Mycoplasma gallisepticum, Carpodacus mexicanus, house finch, genetic bottleneck, epidemic, House Finch Disease Survey

\section{INTRODUCTION}

Identifying variation in host-pathogen dynamics may allow researchers to generate hypotheses regarding key features affecting the influence of pathogens on host populations. One host-disease system in which spatial variation can be examined is the interaction between the bacterium Myco-

Published online:

Correspondence to: André A. Dhondt, e-mail: aad4@cornell.edu plasma gallisepticum (MG) and a wild songbird, the house finch (Carpodacus mexicanus). In 1994, a novel strain of a common poultry pathogen MG, which causes severe conjunctivitis in house finches, emerged in the Washington, DC area and spread rapidly across the eastern North American range of the host species (Fischer et al., 1997; Dhondt et al., 1998). Within a year after its emergence, mycoplasmal conjunctivitis was found across a region of roughly $800,000 \mathrm{~km}^{2}$, and within 3 years after its emergence, the disease had spread over most of the eastern range 
of the host species, roughly 3,000,000 $\mathrm{km}^{2}$ (Fischer et al., 1997; Dhondt et al., 1998). The epidemic caused a severe decrease in host abundance both in local populations (Nolan et al., 1998) and across the entire eastern range of the species (Hochachka and Dhondt, 2000). Using a volunteer-based monitoring scheme, the House Finch Disease Survey (HFDS), Dhondt et al. (1998) were able to document this rapid expansion of the epidemic on a monthly basis. Once the disease had become established, regular seasonal variation in prevalence occurred in local populations (Hartup et al., 2001, Dhondt et al., 2005) and at a regional scale (Altizer et al., 2004).

An apparent difference in host-pathogen dynamics has emerged following the first reports in April 2002 of mycoplasmal conjunctivitis caused by the house-finch strain of MG in western, native house finches. These reports came from a finch population in Missoula, MT that had been studied continuously since 1993 (Duckworth et al., 2003). By April 2004, MG was also confirmed in house finches from Portland, OR (Ley et al., in press). In 2000, we expanded the HFDS in anticipation of the arrival of MG in western North America to document the expansion of the pathogen once it reached the native range of the host species. In this article, we describe the geographic expansion of mycoplasmal conjunctivitis into native, western house finches using HFDS data, and then contrast the disease dynamics between eastern, introduced house finches and western, native populations using prevalence data collected at both local and broad population scales.

\section{Materials And Methods}

\section{Western Local Population Study}

Prevalence data from Missoula, MT were collected in the context of a detailed, long-term population study using individually banded and re-observed house finches in a local population studied since 1993. Detailed study methods are described in Badyaev and Martin (2000). For that population, there are observations for all months except November and December. As a measure of disease prevalence, we calculated the percentage of individuals that were observed with conjunctivitis in the population in any given half-month.

\section{Broad Scale Disease Survey}

To describe the expansion of mycoplasmal conjunctivitis in house finches and to measure its prevalence, we used data collected by thousands of volunteers who participated in the House Finch Disease Survey (HFDS), and Project Feeder Watch (PFW) (Wells et al., 1998; Lepage and Francis, 2002). The methodology of the HFDS is described in detail in Dhondt et al. (1998). In brief, participants can report on a daily basis if they observed house finches and if any observed finches had signs of conjunctivitis. PFW data are reports of observations made at weekly (minimum) intervals, in which observers entering their data over the Internet can specify both the total number of house finches observed as well as the number of house finches with conjunctivitis. PFW disease survey data are only used when observers explicitly report a number of diseased birds (zero or more). In western North America, we defined three geographic regions that had roughly equal numbers of participants: the Northwest (British Columbia, Washington, Oregon, Alberta, Montana, Idaho, and Wyoming), California, and the Southwest (Nevada, Utah, Colorado, Arizona, and New Mexico). Following Altizer et al. (2004), we calculated the proportion of "sick-days" as a monthly index of disease prevalence in each region as the number of days on which a participant observed one or more diseased house finches divided by the number of days on which the participant saw any house finches. We combined data from all participants in a region during a single month and we only included months for which at least 30 observers reported in a region, thereby limiting data on prevalence to the period November-April. The percentage of birds with conjunctivitis in a local population is correlated with the proportion of participants reporting diseased birds (Dhondt et al., 1998) and with the proportion of sick-days in a region (Altizer et al., 2004), so that variation in all three measures reflects variation in disease prevalence, although the absolute levels around which prevalence values vary cannot be compared directly.

\section{Statistical Analyses}

We used SigmaStat 3.1 (Systat Software, Point Richmond, CA, 2004) to carry out $\chi^{2}$ tests and a two-way analysis of variance with the Holm-Sidak test for pairwise a posteriori comparisons of means. We used SAS 9.0 to carry out a logistic regression to compare the change in disease prevalence between regions, modeling the probability of disease as a function of year, region, and a year $\times$ region interaction. A significant interaction term would indicate that the change in prevalence from the year before to the year after 

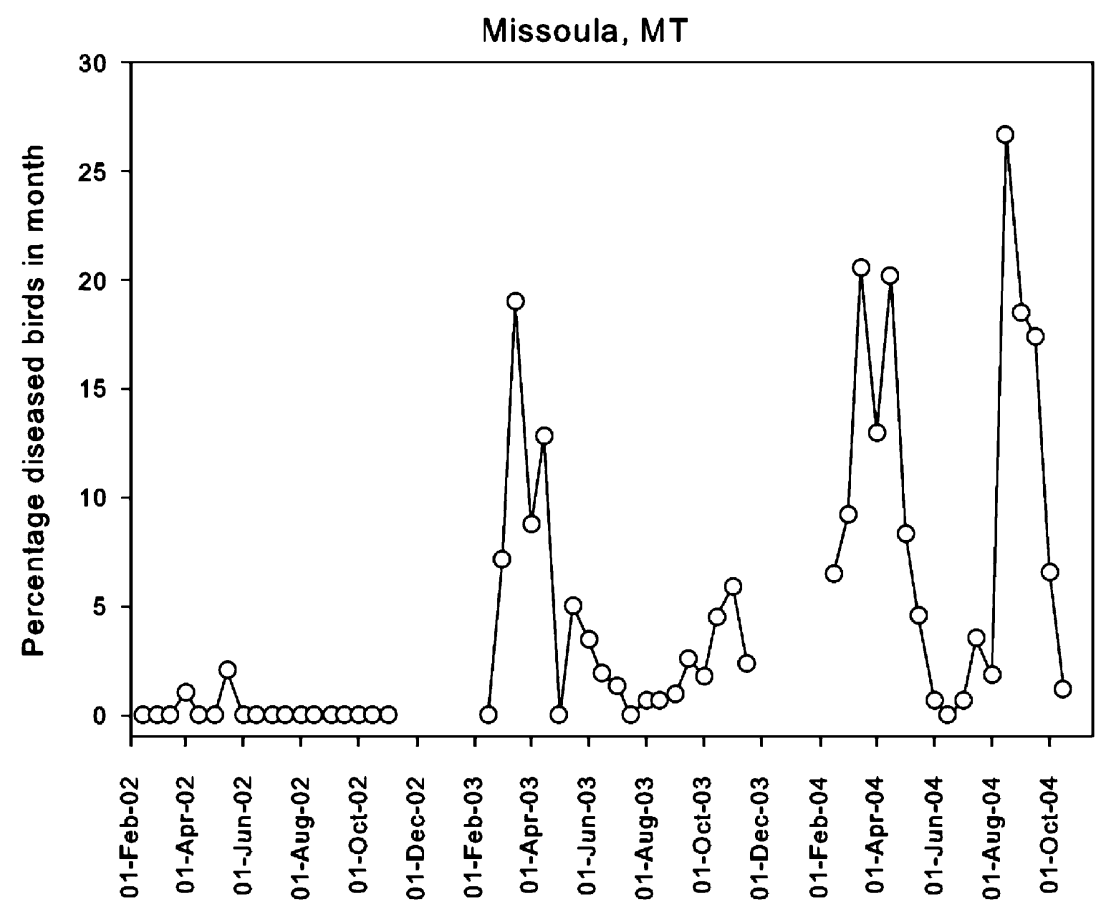

Figure 1. Prevalence of conjunctivitis calculated as the percentage of house finches with disease in a local population in Missoula, Montana (MT). All birds were individually banded, and re-observed frequently. The percentages were calculated per half month. Note how the disease prevalence increases slowly, reaching peak values in spring in all 3 years. the epidemic started in a region would differ between regions. The critical value for acceptance of statistically significant results was set at $\alpha=0.05$.

\section{Results}

\section{Prevalence in a Local Western Population}

In Missoula, MT diseased birds were observed for the first time during April-June 2002 when eight birds were seen with conjunctivitis consistent with MG infection (confirmed by MG PCR) (Duckworth et al., 2003). No diseased birds were observed between July 2002 and February 2003, after which prevalence rose rapidly to a peak of $19 \%$ diseased individuals during the second half of March (Fig. 1; difference spring 2002-2003: $\left.\chi^{2}=23.6,1 \mathrm{df}, P<0.0001\right)$. Prevalence gradually decreased during the breeding season and again returned to $0 \%$ in July. This was followed by a low fall peak reaching $5.9 \%$ in the first half of November (July-Nov 2003: $\chi^{2}=30.4,1 \mathrm{df}, P<0.0001$ ). In spring 2004, prevalence peaked at $20.5 \%$ during the second half of March, a level similar to that in the previous year (spring 2003-2004: $\chi^{2}=0.02,1 \mathrm{df}, \mathrm{NS}$ ) and declined again to $0 \%$ in the second half of June. The fall of 2004 peak, however, was much higher than in the previous year reaching $26.7 \%$ in the second half of August (fall 2003-fall 2004: $\chi^{2}=28.7,1$ df, $P<0.001)$. In 2004, seasonal variation in disease prevalence was similar to that in eastern populations (Al- tizer et al., 2004; Dhondt et al., 2005) with both fall and spring peaks, and breeding season and mid-winter minima.

Even 3 years after the arrival of MG in the Missoula population, the maximum prevalence values remained much lower than those in a banded eastern population where a prevalence of $60 \%$ was observed within less than a year after conjunctivitis was first observed (Nolan et al., 1998).

\section{Prevalence at a Regional Scale}

Although MG was not confirmed in western house finches until 2002, frequent observations of house finches with conjunctivitis were already reported in 2000 in all western regions (Table 1). Between 2000 and 2002, the proportion of sick-days per winter averaged $5.84 \%$ in the Northwest, $3.16 \%$ in California, and $2.73 \%$ in the Southwest. We believe that this background level of conjunctivitis reflects avian pox lesions around the eyes, whose physical signs may easily be mistaken for MG infections, even by trained observers. We use these background levels as a baseline and assume that any dramatic increases in baseline levels following 2002 (when MG was first documented) represent changes in MG prevalence. In November 2003, about 15 months after the first reported case in Missoula, a rapid increase in conjunctivitis prevalence was observed in the Northwest with prevalence values of up to $14.0 \%$ in late winter and early spring. A similar pattern unfolded in the 
Table 1. Conjunctivitis Prevalence per Winter in Three Western Regions

\begin{tabular}{|c|c|c|c|c|c|c|}
\hline \multirow[b]{2}{*}{ Region mean winter } & \multicolumn{2}{|l|}{$\mathrm{CA}$} & \multicolumn{2}{|l|}{ SW } & \multicolumn{2}{|l|}{ NW } \\
\hline & SE & Mean & SE & Mean & SE & Mean \\
\hline $2000-01$ & 3.41 & 0.69 & 4.37 & 0.58 & 7.25 & 0.83 \\
\hline 2001-02 & 2.28 & 0.52 & 1.87 & 0.63 & 6.07 & 0.80 \\
\hline $2002-03$ & 3.78 & 0.67 & 1.95 & 0.27 & 4.21 & 0.75 \\
\hline 2003-04 & 2.77 & 0.64 & 1.97 & 0.70 & 11.35 & 0.97 \\
\hline $2004-05$ & 5.10 & 1.20 & 1.98 & 0.22 & 10.11 & 0.66 \\
\hline
\end{tabular}

CA, California; SW, southwestern region as defined in Materials and Methods; NW, northwestern region.

Table 2. Results of a Two-way Analysis of Variance Comparing Prevalence per Winter in Three Western Regions Using Monthly Prevalence Values

\begin{tabular}{|c|c|c|c|c|c|}
\hline Source of variation & DF & SS & MS & $\mathrm{F}$ & $P$ \\
\hline Region & 2 & 486.658 & 243.329 & 79.725 & $<0.001$ \\
\hline Winter & 4 & 91.846 & 22.962 & 7.523 & $<0.001$ \\
\hline Region $\times$ winter & 8 & 169.548 & 21.193 & 6.944 & $<0.001$ \\
\hline Residual & 75 & 228.907 & 3.052 & & \\
\hline Total & 89 & 976.958 & 10.977 & & \\
\hline
\end{tabular}

DF, degrees of freedom; SS, sum of squares; MS, mean square.

following winter 2004-2005. Through the course of both winters, prevalence increased about twofold above background levels in the Northwest, while it remained at background level in California and in the Southwest (Table 1). The more formal analysis of the data, with a twoway analysis of variance with winter and region as factors, showed that both main effects (year and region) and their interaction were significant (Table 2). A pairwise comparison of the means at the $5 \%$ level showed no significant differences between winters in California or in the Southwest. In the Northwest, however, the mean prevalence values of winters 2003-2004 and 2004-2005 did not differ from each other, but were significantly different from the winters 2000-2001, 2001-2002, and 2002-2003, confirming that prevalence increased only in that region in the winter 2003-2004.

At the regional scale (Fig. 2), prevalence increased much more rapidly in eastern, introduced populations than in western, native populations (Fig. 2). Thus, for example, the proportion of sick-days in Ohio, Illinois, and Indiana combined increased from $0.87 \%$ in February 1995 to $27.90 \%$ in February 1996, compared to a rise in the Northwest between February 2002 and February 2003 from
$6.8 \%$ to $14.2 \%$ (logistic regression year $\times$ region interaction term Wald $\left.-\chi^{2}=9.311, \mathrm{df}=1, P=0.0023\right)$. The rate of geographic expansion also differed between introduced and native regions: the epidemic covered 800,000 $\mathrm{km}^{2} 10$ months after first being observed in the eastern United States and almost 3,000,000 $\mathrm{km}^{2} 3$ years after its emergence (Dhondt et al., 1998). In the western United States, the disease still did not cover more than about 1,000,000 $\mathrm{km}^{2}$ 3 years after first being observed in the region.

\section{Discussion And Conclusions}

Our data suggest that the expansion of the MG epidemic was slow in western North America. After the first cases of mycoplasmal conjunctivitis appeared in house finches in 2002 in Missoula, MT, the epidemic gradually expanded further west during subsequent years. Conjunctival samples in April 2004 and in March 2005 from house finches with conjunctivitis captured in Portland, OR, $800 \mathrm{~km}$ west of Missoula, were diagnosed PCR-positive for MG (Ley et al., in press). MG in house finches thus reached western coastal states, and it is therefore likely that the increase in preva- 


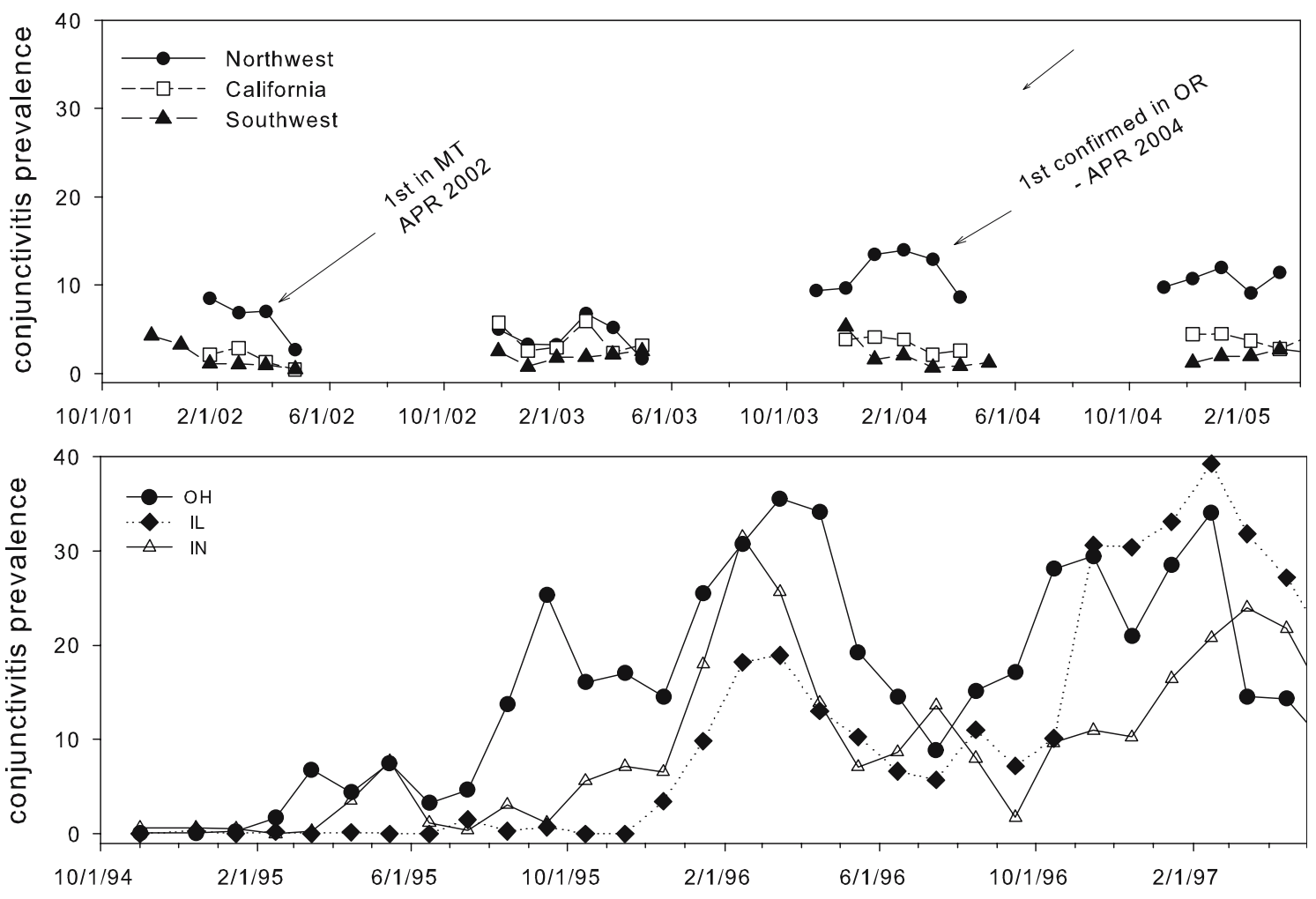

Figure 2. Prevalence of conjunctivitis expressed as the percentage of sick days (see text) in three regions of western North America and in three eastern states $(\mathrm{OH}=$ Ohio, $\mathrm{IL}=$ Illinois, $\mathrm{IN}=$ Indiana $)$. Avian pox can cause lesions around the eyes that are very similar to those caused by Mycoplasma gallisepticum (MG) infections, and we argue

lence of conjunctivitis in house finches in the Northwest was the result of the westward progression of the epidemic.

Similarly, even at a local level, the increase in disease prevalence and maximum prevalence in Missoula, MT (Fig. 1) was slower than that seen in intensively-studied eastern populations. Less than a year after the first birds with conjunctivitis were observed in Auburn, AL, $60 \%$ of the house finches captured for banding and observed at feeders showed signs of mycoplasmal conjunctivitis (Nolan et al., 1998). In another eastern population in Atlanta, GA, in 2001, 6-7 years after MG reached the area, the peak prevalence still surpassed $50 \%$ of the birds trapped (Dhondt et al., 2005). In contrast, in Missoula, 1 year after the epidemic started, only about $20 \%$ of the birds showed disease, and 2.5 years after mycoplasmal conjunctivitis was first observed, only $26 \%$ of individuals had conjunctivitis. In the Missoula population, therefore, prevalence increased at a much lower rate and reached a much lower maximum level than in eastern populations (Fig. 1). Not only did the epidemic expand much more slowly in the West and that the relatively high pre-MG levels of conjunctivitis reported by participants of the House Finch Disease Survey reflect this. Beginning in the winter of 2003-2004, prevalence of conjunctivitis increased markedly in the Northwest (where MG had been detected in MT and in Oregon [OR]).

debilitated a smaller proportion of individuals in local populations, we also have no evidence, so far, that house finch abundance declined in the Northwest following the MG epidemic. It may, however, be too soon to detect such an effect because, in the East, a $60 \%$ decline in house finch numbers was apparent 2.5-3 years after the epidemic reached high prevalence levels (Hochachka and Dhondt, 2000).

In the West, the presence of avian pox complicated description of changing prevalence of MG-induced conjunctivitis. Avian pox may cause physical signs that are difficult to distinguish from those caused by MG. McClure (1989) described the prevalence of avian pox based on 11,000 house finches trapped in Ventura County, CA. He noted a high prevalence of pox, especially in winter. Although most lesions were on the legs or feet, about $10 \%$ of infected birds showed lesions around the bill and $8 \%$ around the eyes. These latter lesions could easily be confounded with the physical signs caused by MG, even by a trained observer. In fact, we sampled the eyes of three 
house finches showing distinct signs of conjunctivitis in Lafayette Co., CA during March of 2004, but all tested negative for MG by our PCR-based assay. This led us to examine changes in prevalence of conjunctivitis relative to baseline (presumably pox-induced) levels of conjunctivitis in western North America (Table 1) before MG was found in this region. In the eastern United States, pox lesions are rare (Hartup et al., 2004) [and own observations]. We believe HFDS data described the expansion of the MG epidemic in the western United States because HFDS data did not yet show an increase in conjunctivitis prevalence in California nor in the Southwest (Fig. 2), whereas we found a substantial increase in prevalence in the Northwest, where the presence of MG had also been confirmed by PCR testing both in Montana and in Oregon.

Understanding the factors that mediate the likelihood of pathogen epidemics in host populations remains a question of general and timely importance in disease ecology (Woolhouse et al., 2005). The factors that influence the likelihood that pathogens cause major epidemics in their hosts include variation in host ecology, cross immunity, behavior, and genetics, as well as changes in pathogen genetics (Woolhouse et al., 2005). A small number of field studies have shown that in the same population, genetically less variable individuals are more likely to be affected by pathogens than those that are more genetically variable (Lively et al., 1990; Coltman et al., 1999; Acevedo-Whitehouse et al., 2003; MacDougall-Shackleton et al., 2005). Similarly, only a small number of studies have related genetic diversity at the population-level in geographically distinct populations with parasite burdens (Meagher, 1999) or pathogen susceptibility (Pearman and Garner, 2005). Assuming that pathogen success is mitigated by host genetic variation, it is particularly interesting to compare epidemics in different parts of a host's range between which genetic diversity differs, although no studies have done this so far.

Although our evidence is indirect, and other factors certainly contributed to differences in MG expansion in eastern and western populations, we believe that our data strongly suggest that genetic factors have played a role. Five sampled eastern populations of house finches harbor, on average, $17.5 \%$ lower allelic richness and $4.9 \%$ lower heterozygosity levels than four western populations (Hawley et al., 2006). These genetic differences almost certainly resulted from the strong demographic bottleneck that occurred during the introduction of house finches to the eastern United States (Elliott and Arbib, 1953). Further- more, variation in disease susceptibility among individuals in the eastern population has been directly linked to differences in heterozygosity (Hawley et al., 2005), indicating that genetic variation at the scale of the individual mediates disease susceptibility in this system. Our disease prevalence data suggest that relationships between genetic variation and disease susceptibility may be equally important at the population level. Our results are consistent with the idea that the epidemic of the emerging mycoplasmal conjunctivitis expanded more slowly, and that a smaller proportion of birds developed disease among genetically more variable native birds than among the genetically less variable introduced host populations that passed through a demographic bottleneck after introduction.

However, as Woolhouse et al. (2005) pointed out, nongenetic factors can also contribute to differences in $\mathrm{R}_{0}$ and hence in the rate at which emerging diseases spread. These include host behavior, host ecology, pathogen genetics, pathogen ecology, and host cross immunity. As regards host ecology, two factors could slow down the rate at which the epidemic spread among western house finches compared to eastern birds: western populations, if they migrate at all, exhibit lower prevalence of migration than eastern birds (Able and Belthoff, 1998). The geography of the West, with high mountain ranges running North-South could reduce dispersal from East to West. These factors could explain differences in the rate of spread of the pathogen, but would not explain why the increase in prevalence in a local population was slower. Additionally, house finches in the West are less clumped in urban and suburban environments than in the East, and overall density and social group sizes appear to be lower (unpublished data from PFW). Both factors would affect transmission rates and pathogen persistence, and could explain differences both in the rate of spread and in the prevalence level reached.

Pathogen-related differences may also account for some of the observed differences in disease dynamics. We know very little about pathogen genetics and ecology including whether the MG strain that arrived in the West is genetically different. Given that genetic variation is appearing among MG samples taken in the East, examining the genetics of the pathogen in native house finch populations as well as its resulting disease course in the host could yield important insights (Pillai et al., 2003; Cherry et al., in press). Finally, climatic conditions in the West could be sufficiently different from those in the East to affect pathogen fomite survival outside the host and thereby influence the probability of disease transmission. MG sur- 
vival on dry surfaces, as are characteristic in the western United States, is longer at lower temperatures than at higher temperatures in experimental conditions (Nagatomo et al., 2001). Finally, the higher prevalence of other pathogens in western populations (such as avian pox) might be partially protective against the novel pathogen, thereby slowing down its spread and reducing the $\mathrm{R}_{0}$ value.

Although some or all of these factors might contribute to differences in the epidemic in eastern and western house finches, the slow rate at which disease prevalence increased in the local population in Missoula, where the density is high and where avian pox has not been observed, strongly suggests that host genetic factors are the main cause of the differences in pathogen-host dynamics in the different parts of the host range. Further research, however, is needed to determine the relative importance of all factors that may contribute to the observed differences in disease expression in native and introduced parts of the host range.

\section{ACKNOWLEDGMENTS}

The authors acknowledge funding from the National Science Foundation (grant no. DEB-0094456) as part of the NIH-NSF Ecology of Infectious Diseases program. A.V.B.'s work in Montana was supported by NSF grants DEB-0075388, IBN-0218313, and DEB-0077804. Any opinions, findings, and conclusions or recommendations expressed in this material are those of the authors and do not necessarily reflect the views of the National Science Foundation. The authors are grateful to the thousands of volunteers who have contributed data to the House Finch Disease Survey and to two anonymous reviewers who provided helpful comments.

\section{REFERENCES}

Altizer S, Hochachka WM, Dhondt AA (2004) Seasonal dynamics of mycoplasmal conjunctivitis in eastern North American House Finches. Journal of Animal Ecology 73:309-322

Able KP, Belthoff JR (1998) Rapid 'evolution' of migratory behaviour in the introduced house finch of eastern North America. Proceedings of the Royal Society, London, Series B 265:2063-2071

Acevedo-Whitehouse K, Gulland F, Greig D, Amos B (2003) Disease susceptibility in California sea lions. Nature 422:35

Badyaev AV, Martin TE (2000) Sexual dimorphism in relation to current selection in the house finch. Evolution 54:987-997
Cherry JJ, Ley DH, Altizer S (2006) Genotypic analyses of Mycoplasma gallisepticum isolates from songbirds by random amplification of polymorphic DNA and amplified-fragment length polymorphism. Journal of Wildlife Diseases 42 (in press)

Coltman DW, Pilkington JG, Smith JA, Pemberton JM (1999) Parasite-mediated selection against inbred Soay sheep in a freeliving, island population. Evolution 53:1259-1267

Dhondt AA, Altizer S, Cooch EG, Davis AK, Dobson A, Driscoll MJL, et al. (2005) Dynamics of a novel pathogen in an avian host: mycoplasmal conjunctivitis in house finches. Acta Tropica 94:77-93

Dhondt AA, Tessaglia DL, Slothower RL (1998) Epidemic mycoplasmal conjunctivitis in house finches from eastern North America. Journal of Wildlife Diseases 34:265-280

Duckworth RA, Badyaev AV, Farmer KL, Hill GE, Roberts SR (2003) First case of mycoplasmosis in the native range of the house finch (Carpodacus mexicanus). Auk 120:528-530

Elliott JJ, Arbib S (1953) Origin and status of the house finch in the eastern United States. Auk 70:31-37

Fischer JR, Stallknecht DE, Luttrell MP, Dhondt AA, Converse KA (1997) Mycoplasmal conjunctivitis in wild songbirds: the spread of a new contagious disease in a mobile host population. Emerging Infectious Diseases 3:69-72

Hartup BK, Bickal JM, Dhondt AA, Ley DH, Kollias GV (2001) Dynamics of conjunctivitis and Mycoplasma gallisepticum infections in house finches. Auk 118:327-333

Hartup BK, Stott-Messick B, Guzy M, Ley DH (2004) Health survey of house finches (Carpodacus mexicanus) from Wisconsin. Avian Diseases 48:84-90

Hawley DM, Sydenstricker KV, Kollias GV, Dhondt AA (2005) Genetic diversity predicts pathogen resistance and cell-mediated immunocompetence in house finches. Biology Letters 1:326-329

Hawley DM, Hanley D, Dhondt AA, Lovette IJ (2006) Molecular evidence for a founder effect in invasive house finch (Carpodacus mexicanus) populations experiencing an emergent disease epidemic. Molecular Ecology 15:263-275

Hochachka WM, Dhondt AA (2000) Density-dependent decline of host abundance resulting from a new infectious disease. Proceedings of the National Academy of Sciences of the USA 97:5303-5306

Lepage D, Francis CM (2002) Do feeder counts reliably indicate bird population changes? 21 years of winter bird counts in Ontario, Canada. Condor 104:255-270

Ley DH, Sheaffer DS, Dhondt AA (2006) Further western spread of Mycoplasma gallisepticum infection of house finches. Journal of Wildlife Diseases 42 (in press)

Lively CM, Craddock C, Vrijenhoek RC (1990) Red Queen Hypothesis supported by parasitism in sexual and clonal fish. Nature 344:864-866

MacDougall-Shackleton EA, Derryberry EP, Foufopoulos J, Dobson AP, Hahn TP (2005) Parasite-mediated heterozygote advantage in an outbred songbird population. Biology Letters 1:105-107

McClure HE (1989) Epizootic lesions of house finches in Ventura County, California. Journal of Field Ornithology 60:421-430

Meagher S (1999) Genetic diversity and Capillaria hepatica (Nematoda) prevalence in Michigan deer mouse populations. Evolution 53:1318-1324

Nagatomo H, Takegahara Y, Sonoda T, Yamaguchi A, Uemura R, Hagiwara S, et al. (2001) Comparative studies of the persistence 
of animal mycoplasmas under different environmental conditions. Veterinary Microbiology 82:223-232

Nolan PM, Hill GE, Stoehr AM (1998) Sex, size, and plumage redness predict house finch survival in an epidemic. Proceedings of the Royal Society, London, Series B 265:961-965

Pearman PB, Garner TWJ (2005) Susceptibility of Italian agile frog populations to an emerging strain of Ranavirus parallels population genetic diversity. Ecology Letters 8:401-408

Pillai SR, Mays HL, Ley DH, Luttrell P, Panangala VS, Farmer KL, et al. (2003) Molecular variability of house finch Mycoplasma gallisepticum isolates as revealed by sequencing and restriction fragment length polymorphism analysis of the pvpA gene. Avian Diseases 47:640-648

Wells JV, Rosenberg KV, Dunn EH, Tessaglia-Hymes DL, Dhondt AA (1998) Feeder counts as indicators of spatial and temporal variation in winter abundance of resident birds. Journal of Field Ornithology 69:577-586

Woolhouse MEJ, Haydon DT, Antia R (2005) Emerging pathogens: the epidemiology and evolution of species jumps. Trends in Ecology and Evolution 20:238-244 